\title{
THE MATHEMATICAL ASSOCIATION
}

The fundamental aim of the Mathematical Association is to promote good methods of mathematical teaching. A member receives each issue of one or more of The Mathematical Gazette, Mathematics in School, Primary Mathematics (according to the class of membership chosen), together with Newsletters. Reports are published from time to time and these are normally available to members at a reduced rate. Those interested in becoming members should contact MA Headquarters for information and application forms. The address of the Association Headquarters is 259 London Road, Leicester LE2 3BE, UK (telephone 0116221 0013). The Association should be notified of any change of address. If copies of the Association periodicals fail to reach a member through lack of such notification, duplicate copies can only be supplied at the published price. If change of address is due to a change of appointment, the Association will be glad to be informed. Subscriptions should be submitted to the Treasurer via Headquarters. Correspondence relating to Teaching Committee should be addressed to Mrs Mel Muldowney. The Association's Library is housed in the University Library, Leicester.

Views expressed in the Mathematical Gazette by authors or advertisers are not necessarily those of the Association.

\section{THE MATHEMATICAL GAZETTE}

Editor:

Dr Gerry Leversha,

15 Maunder Road,

Hanwell,

London W7 3PN

g.leversha@btinternet.com

Production Editor:

Mr Bill Richardson,

Kintail,

Longmorn,

Elgin IV30 8RJ

wpr3145@gmail.com
Problem Corner:

Mr Nick Lord,

Tonbridge School,

Tonbridge,

Kent TN9 1JP

njl@tonbridge-school.org

Reviews Editor:

Mr Owen Toller,

4 Caldwell House,

48 Trinity Church Road,

London SW13 8EJ

owen.toller@btinternet.com

Potential advertisers should send an e-mail to: advertisingcontroller@m-a.org.uk

Material for publication should be sent to the Editor.

Books for review should be sent to the Reviews Editor.

Advice to authors of notes and articles.

Study the format of articles in the Gazette. Please note the format for references, which should be listed in their order of appearance in an article. MSS may be submitted electronically, preferably in pdf format, or, if sent by post, should be typed and two copies included. (Mathematical expressions may be hand written.) Please send by e-mail not on floppy discs. This edition of the Gazette was produced on an Acorn machine using TechWriter and Draw.

10.1017/mag.2019.96 


\section{CONTENTS (continued)}

Notes 103.15 to 103.27

When is the sum of the first $n$ consecutive Paul Stephenson

odd cubes a square?

Variations on a theme

Russell A. Gordon

306

An unexpected closed form revisited

J. A. Scott

Trigonometric addition and subtraction

David Gau

formulas, a unified visual approach

Bernoulli's inequality for negative exponents Horia Vîjîitu

Geometric problems leading to power means Russell A. Gordon

Closed form evaluation of a class of

Paul Levrie improper integrals

On a problem of Sastry and a theorem of Serenus Mowaffaq Hajja

On Pitot's theorem

Martin Josefsson

Partitions, geometric progressions and a Shane Chern, Shiqiu Qiu

Putnam problem

An extension of Thébault's second problem Raymond Viglione

A proof of Clarke's conjecture Emrah Kiliç, Talha Arikan 346

A property of a particular unit-distance graph Martin Griffiths

\section{Teaching Note}

How is the scalar product derived?

Frank A. Greco

Problem Corner

Nick Lord

Student Problems

Stan Dolan

Reviews 


\section{CONTENTS}

\section{Articles}

Sir Michael Francis Atiyah, O.M.

Geoffrey Howson

Locating parameters of interest in a conic section

Teaching proofs without words using dynamic geometry

Moshe Stupel, Avi Sigler, 204 Jay Jahangiri

Robert L. Lamphere

A hyperbolic proportionality theorem and hyperbolic surveying problems

New points that belong to the nine-point circle David Fraivert

Pascal-points quadrilaterals inscribed in a David Fraivert cyclic quadrilateral

Finding the probability of a rare real world event John Wiorkowski

The need for closure

Christopher D. Hollings

Linear differential equations with constant Bethany Fralick and coefficients Reginald Koo

Latin square matrices and their inverses

K. Robin McLean

Launching a projectile to cover maximal area Robert Kantrowitz and Michael M. Neumann

Rounding versus truncation estimates in difference calculations

Leonard van Wyk

(C) The Mathematical Association 2019

Typeset by Bill Richardson

\section{CAMBRIDGE UNIVERSITY PRESS}

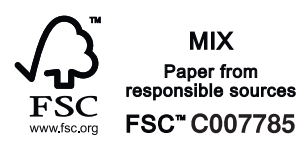

Printed in the UK by Bell \& Bain Ltd. 